\title{
A Superior Mixed Electron and Carbonate-ion Conducting Metal-carbonate Composite Membrane for Advanced Flue-gas Carbon Capture
}

\author{
Jie Fang, Jingjing Tong and Kevin Huang* \\ Department of Mechanical Engineering, University of South Carolina, Columbia, SC 29208 \\ *Corresponding author: Huang46@cec.sc.edu
}

\begin{abstract}
Developing cost-effective, energy-efficient and $\mathrm{CO}_{2}$-selective advanced carbon capture technologies for carbon intensive flue gas is of vital importance to the reduction of carbon pollution and mitigation of global climate change. In the present work, we report that an electrochemistry-based mixed electron and carbonate-ion conducting metal-carbonate composite membrane with porous metal matrix fabricated by a chemical dealloying method exhibits superior $\mathrm{CO}_{2} / \mathrm{O}_{2}$ flux density and stability over a 900-hour testing period. The results also demonstrate that the presence of $\mathrm{H}_{2}$ in the sweeping gas can significantly enhance the $\mathrm{CO}_{2}$ flux density as a result of increased gradient of chemical potential of oxygen and produce a pure stream of $\mathrm{CO}_{2}$ and $\mathrm{H}_{2} \mathrm{O}$ for easy downstream conversion. The fundamental mechanisms leading to the superior performance are also discussed.
\end{abstract}

Keywords: carbon capture; membrane; metal; carbonate; electrochemical 


\section{Introduction}

Carbon capture and storage (CCS) has been established as a key technology to curb $\mathrm{CO}_{2}$ emission from fossil-fueled power plants, thus to mitigate global climate change that has been increasingly observed to impact our daily life and damage our economy in recent human history. The core of the CCS technology is to capture $\mathrm{CO}_{2}$ at emission sources and geologically bury it for permanent storage or enhanced oil recovery (OER) $[1,2]$. As the

first step of CCS, carbon capture has been developed for three power-generation related combustion processes that are responsible for $\sim 78 \%$ of the global stationary carbon emissions: pre-combustion, post-combustion and oxy-combustion [3-10]. A major challenge to the full implementation of the current carbon capture technologies such as imine-based "chemical washing" process is, however, the high energy penalty, which significantly reduces plant efficiency and increases the cost of electricity. Developing cost-effective, energy-efficient and $\mathrm{CO}_{2}$-selective carbon-capture processes/methods is, therefore, highly desirable.

Electrochemical methods have been increasingly investigated as a new approach to capture $\mathrm{CO}_{2}$ from combustion products such as flue gas in recent years. One approach is to use molten carbonate fuel cells (MCFCs) operated under a reverse mode that relies upon electricity as the driving force to concentrate $\mathrm{CO}_{2}$ from a carbon source $[11,12]$. While such a high-temperature electrolysis process (or "electrical pump") can achieve high efficiency and selectivity, the requirement for electricity and external electronics complicates the system design and thus raises the overall system cost. 
With a similar electrochemical principle, our group as well as others recently proposed two new types of carbon capture membranes made of ceramic-carbonate and metalcarbonate dual-phase composites [13-31]. The driving force for these new membranes is the gradient of electrochemical potential(s) of $\mathrm{CO}_{2}$ (and $\mathrm{O}_{2}$ ) existing on the opposite surfaces of the membranes. No electricity, thus no external electronics, is needed to drive $\mathrm{CO}_{2}$ through the membrane, making it a promising low-cost carbon capture option. Ceramic-carbonate membranes consist of an oxide-ion conductor (ceramic) and carbonate-ion (molten carbonate denoted as MC hereinafter) conductor and follow upon the reversible electrochemical reaction $\mathrm{CO}_{2}+\mathrm{O}^{2-}=\mathrm{CO}_{3}{ }^{2-}$ at the opposite surfaces to separate $\mathrm{CO}_{2}$ from a carbon source. Similarly, metal-carbonate membranes comprise of an electron (metal) and carbonate-ion (MC) conductor and follow upon the reversible electrochemical reaction $\mathrm{CO}_{2}+1 / 2 \mathrm{O}_{2}+2 \mathrm{e}^{-}=\mathrm{CO}_{3}{ }^{2-}$ to separate $\mathrm{CO}_{2}$. Previous studies have demonstrated that these two types of membranes are effective separators of $\mathrm{CO}_{2}$ for flue gas, natural gas and fuel gas with high flux and excellent selectivity [13-31].

Of the these two electrochemical membranes, metal-carbonate based mixed electron and carbonate-ion conductor (MECC) membranes are of particular interest due to their ability to capture $\mathrm{CO}_{2}$ from flue gas (a mixture of $\mathrm{CO}_{2}, \mathrm{O}_{2}, \mathrm{H}_{2} \mathrm{O}, \mathrm{N}_{2}$ ) emitted from coal-fired power plants, a major stationary $\mathrm{CO}_{2}$ emission source $[18-21,29]$. The reversible electrochemical reaction $\mathrm{CO}_{2}+1 / 2 \mathrm{O}_{2}+2 \mathrm{e}^{-}=\mathrm{CO}_{3}{ }^{2-}$ takes place at the two opposite surfaces of the membrane with the forward reaction (left $\rightarrow$ right) occurring at the feed gas surface and backward reaction (right $\rightarrow$ left) occurring at the permeate surface. However, one of the major obstacles hindering MECC membranes from being demonstrated at a larger scale is their long-term instability. Our previous studies have shown that the root-cause 
for the instability of a silver-carbonate membrane is closely related to the large pore size within the silver matrix synthesized by a traditional pore-former method [18-21]; the large pores cannot generate a sufficient capillary force to immobilize molten carbonate during high-temperature operation, resulting in a gradual loss of carbonate and thus degradation of flux. In addition, large pores of low-surface-area yield a low density of triple phase boundaries (TPBs), a critical factor determining the rate of permeation, thus leading to a lower $\mathrm{CO}_{2} / \mathrm{O}_{2}$ flux density.

In the present study, we report that flux density and stability of a silver-carbonate MECC membrane can be substantially enhanced by fabricating the microstructure of porous silver matrix with a chemical dealloying approach, a well-known method to produce nanoporous metal structures for various applications [32]. This is the first study that utilizes chemical dealloying derived porous metal substrates for carbon capture. The resultant submicron pores in the silver matrix are expected to offer high density of TPBs and increase the capillary force to reinforce the immobilization of molten carbonate that resides inside pores, thus improving both the magnitude and stability of the permeation flux. In addition, we also report for the first time the effect of $\mathrm{H}_{2}$ in the sweeping gas on the $\mathrm{CO}_{2} / \mathrm{O}_{2}$ flux density, laying ground for future use of reducing gas to capture $\mathrm{CO}_{2}$ and $\mathrm{O}_{2}$, producing a stream of $\mathrm{CO}_{2}$ and $\mathrm{H}_{2} \mathrm{O}$ for easy downstream conversion.

\section{Experimental procedures}

\subsection{Preparation of Ag-carbonate membranes}


The metal of choice for MECC membrane is Ag, which is chemically inert to MC [18]. The first step to prepare an Ag-carbonate composite membrane is to fabricate a porous Ag matrix into which the MC phase can be impregnated. Chemical dealloying technique was employed with a goal of making nanoporous silver matrix to enhance the retention of MC. The alloy of choice for chemical dealloying is 50at\% Ag and 50at\% Al (from ACI Alloys, denoted as Ag50A150 hereinafter) with $\mathrm{Al}$ as the fugitive element. The dealloying procedure is described as follows. $\mathrm{Ag}-\mathrm{Al}$ alloy pellets in a diameter of $\phi 17 \mathrm{~mm}$ are first soaked in a hot $3 \mathrm{M} \mathrm{HCl}$ aqueous solution at $90^{\circ} \mathrm{C}$ for a predefined period of time ( $48 \mathrm{~h}$ and $72 \mathrm{~h}$ ). The samples synthesized are denoted as $48 \mathrm{~h}-$ Ag50A150 and 72h-Ag50A150, respectively. Then the de-aluminized samples are thoroughly washed in an ultrasonic cleaner with DI water. The samples are finally dried in oven and annealed at $650^{\circ} \mathrm{C}$ for 2 hours. The total weight losses for the $48 \mathrm{~h}$ - and 73 -h dealloyed samples are $\sim 12 \%$ and $15 \%$, equivalent to a pore volume of $29.6 \%$ and $37 \%$, respectively.

The second step to prepare an Ag-carbonate composite membrane is to infiltrate molten carbonate into the porous Ag matrix. The impregnation procedure is described as follows. The porous Ag pellets are first suspended by a silver wire over a carbonate bath containing a eutectic composition of alkaline carbonate mixture: $52 \mathrm{~mol} \% \mathrm{Li}_{2} \mathrm{CO}_{3}$ and $48 \mathrm{~mol} \% \mathrm{Na}_{2} \mathrm{CO}_{3}$. After reaching $650^{\circ} \mathrm{C}$ and melting of the carbonate, the porous matrix is slowly immersed into the carbonate melt and soaked for $2 \mathrm{~h}$. The MC-saturated Ag pellet is finally pulled out of the melt at $600^{\circ} \mathrm{C}$ during the cooling process. The final product of membrane is surface polished with sandpaper using ethanol as a medium to remove any residual molten carbonate.

\subsection{Permeation measurement}


The flux densities of $\mathrm{CO}_{2}$ and $\mathrm{O}_{2}$ were measured with a homemade permeation cell. Details of the experimental setup can be found in our early studies [18, 20]. A brief description is as follows. The MECC membrane was first sealed to a supporting alumina tube by silver paste sealant (synthetic resins, Shanghai Research Institute), followed by bonding a second short alumina tube on the top; this short alumina tube was used to confine the feed gas to the surface of Ag-MC membrane. Ag paste is applied in a layer-by-layer manner. After each application, the assembly is dried at $130^{\circ} \mathrm{C}$ for an hour. A complete seal usually requires $4 \sim 5$ applications. For all the measurements, a simulated flue gas containing $15 \% \mathrm{CO}_{2}, 10 \% \mathrm{O}_{2}$ and $75 \% \mathrm{~N}_{2}$ was used as the feed gas, while Ar with different $\mathrm{H}_{2}$ concentrations $(0,4.35 \%$ and $9.41 \%)$ was used as the sweep gas. The temperature range studied was 550 to $700^{\circ} \mathrm{C}$. The long-term stability testing was conducted at $600^{\circ} \mathrm{C}$ with $9.41 \% \mathrm{H}_{2}-\mathrm{Ar}$ as the sweep gas and the aforementioned simulated flue gas as the feed gas.

A commercial mass flow controller (Smart-Trak, 50 series) was employed to control the gas flow. A Micro-GC (model 490, Agilent Technologies) was used to analyze the compositions of the sweep gas at room temperature and ambient pressure $\left(\mathrm{T}=25^{\circ} \mathrm{C}, \mathrm{P}=1 \mathrm{~atm}\right)$. Prior to use, it was precalibrated with five standard gases of interest $\left(\mathrm{CO}_{2}, \mathrm{O}_{2}, \mathrm{~N}_{2}, \mathrm{H}_{2}\right.$ and $\left.\mathrm{CO}\right)$. The $\mathrm{N}_{2}$ concentration in the sweep gas was used to correct for the leakage from sealing or membrane itself. The flow rate of the sweep gas, regardless of the $\mathrm{H}_{2}$ concentration, was set to $50 \mathrm{ml} / \mathrm{min}$, and that of the feed gas was 100 set to $\mathrm{ml} / \mathrm{min}$. The final $\mathrm{CO}_{2}$ and $\mathrm{O}_{2}$ flux densities were calculated from a leakagecorrected gas composition collected and averaged from ten successive readings by Micro-GC and the known sweep-gas flow rate. A 20-minute stabilization period was given before a measurement was taken at each temperature. 


\subsection{Other characterization}

The phase compositions of the original and de-aluminized samples were examined by an X-ray diffractometer (Rigaku, Japan) equipped with a graphite-monochromatized CuKa radiation $\left(\lambda=1.5418 \AA\right.$ ). The $2 \theta$ scans were performed at a rate of $10^{\circ} \mathrm{min}^{-1}$ in a range of 20 to $80^{\circ}$.

The microstructural features of the porous Ag matrix as well as Ag-MC membrane before and after long-term test were captured by a field emission scanning electron microscopy (FESEM, Zeiss Ultra) equipped with energy dispersive X-ray spectroscopy (EDS) analyzer. The BET surface areas of the dealloyed porous Ag matrix were measured by Krypton adsorption using Autosorb-iQ from Quantachrome Instruments.

\section{Results and discussion}

\subsection{Phases in the original alloy and de-aluminized silver matrix}

According to the Ag-Al phase diagram [33, 34], the starting 50at\%Ag-50at\%Al alloy (denoted as Ag50A150 hereinafter) contains a minor $\alpha$-Al and primary $\gamma$ - $\mathrm{Ag}_{2} \mathrm{Al}$ phase. Fig.1 shows x-ray diffraction (XRD) patterns of the original alloy confirming the presence of primary $\gamma-\mathrm{Ag}_{2} \mathrm{Al}$ and minor $\alpha$-Al phase. After de-aluminizing, the primary phase in the sample is silver with a very small amount of $\gamma-\mathrm{Ag}_{2} \mathrm{Al}$ phase. The small residual $\gamma-\mathrm{Ag}_{2} \mathrm{Al}$ phase is not a concern because $\mathrm{Al}$ element when oxidized into $\mathrm{Al}_{2} \mathrm{O}_{3}$ is an excellent wetting agent for molten carbonates $[23,31]$. 


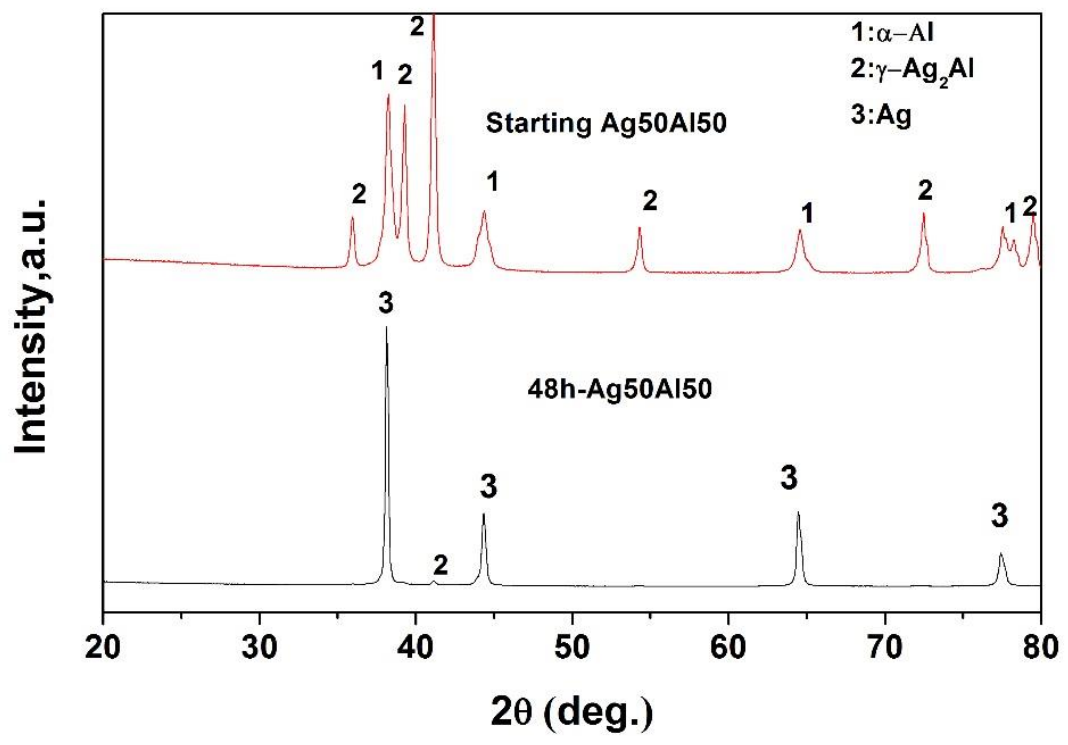

Fig.1 XRD patterns of (a) the original Ag50A150 alloy (b) de-aluminized silver after 48h

\subsection{Microstructure of the de-aluminized porous silver matrix}

The microstructure of the original Ag50A150 alloy is shown in Fig.2 (a), revealing that the minor $\alpha-\mathrm{Al}$ phase is preferentially located between large circular grains of the primary $\gamma-\mathrm{Ag}_{2} \mathrm{Al}$ phase. The microstructures of porous $\mathrm{Ag}$ matrix after de-aluminizing in a hot $3 \mathrm{M}$ $\mathrm{HCl}$ aqueous solution at $90^{\circ} \mathrm{C}$ for $48 \mathrm{~h}$ (denoted as $48 \mathrm{~h}-\mathrm{Ag} 50 \mathrm{Al} 150$ ) are shown in Fig.2 (b)(d). During a typical de-aluminizing process, dissolution of $\mathrm{Al}$ is expected to start first in the intergranular region [35], forming open 3D channels as indicated in Fig.2 (b). These channels provide pathways for further dissolving of $\mathrm{Al}$ in the minor $\alpha-\mathrm{Al}$ as well as primary $\gamma-\mathrm{Ag}_{2} \mathrm{Al}$ phase. Since $\mathrm{Al}$ is much richer in $\alpha-\mathrm{Al}$ than in $\gamma-\mathrm{Ag}_{2} \mathrm{Al}$ (according to the phase diagram), the rate of de-aluminizing and thus pore size due to the $\alpha$-Al phase are expected to be faster and greater than those in the $\gamma-\mathrm{Ag}_{2} \mathrm{Al}$ phase, respectively. Comparison of Fig.2 (c) and (d) indeed indicates that the average pore size in the region 
belonging to $\alpha$-Al phase is in the range of few to tens $\mu \mathrm{m}$, whereas it is $<1 \mu \mathrm{m}$ for the $\gamma$ $\mathrm{Ag}_{2} \mathrm{Al}$-belonging regions. In addition, pores in the $\gamma-\mathrm{Ag}_{2} \mathrm{Al}$ phase region are circular in shape whereas they appear to be laminar in the $\alpha$-Al phase region. Overall, the $\gamma-\mathrm{Ag}_{2} \mathrm{Al}-$ derived porous Ag constitutes a much larger volume of finer pores than the $\alpha$-Al-derived counterpart, which turns out to be the fundamental reason for the high and stable $\mathrm{CO}_{2}$ and $\mathrm{O}_{2}$ flux densities to be shown below.

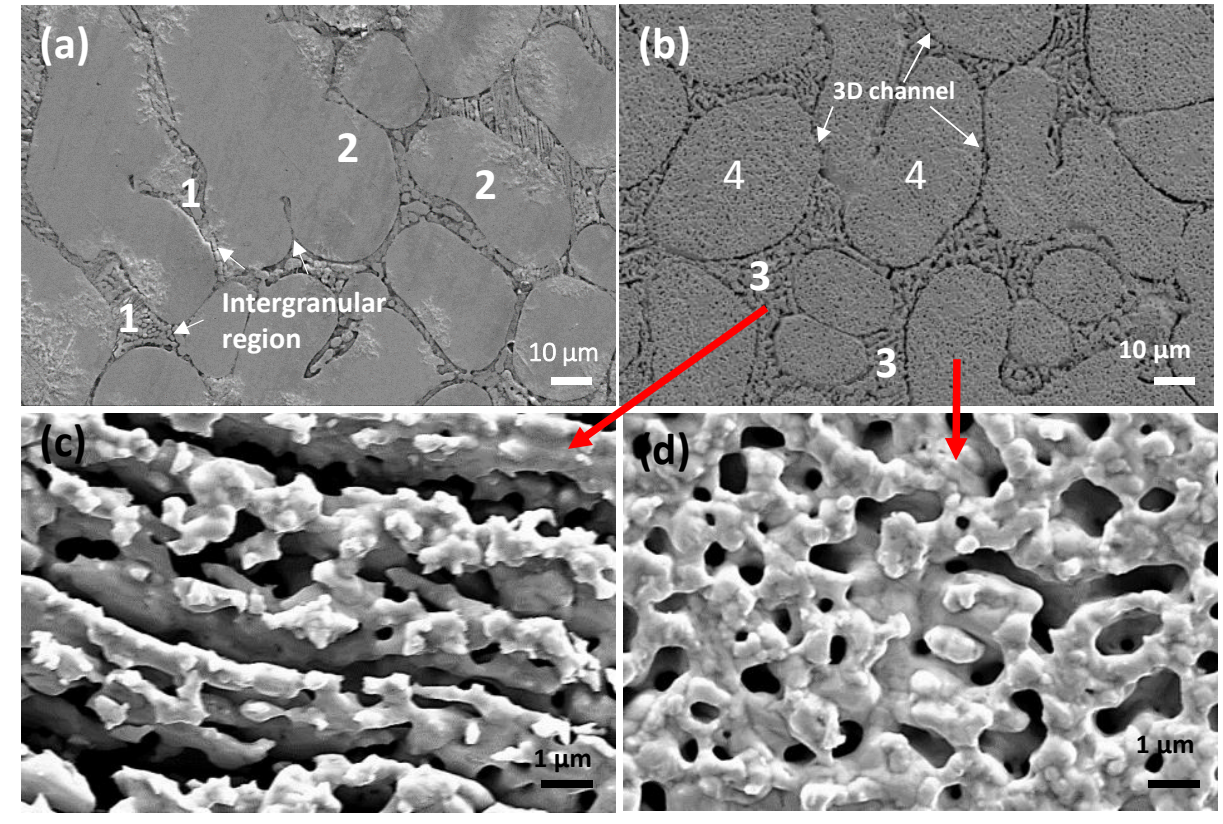

Fig. 2 Microstructures of (a) $\mathrm{Ag} 50 \mathrm{Al} 50$ (eached in $3 \mathrm{M} \mathrm{HCl}$ at $90^{\circ} \mathrm{C}$ for $3 \mathrm{~min}$ to reveal grains and grainboundaries); (b)48h-Ag50Al50 (overall); (c) $\alpha$-Al-derived porous $\mathrm{Ag}$ matrix;(d) $\gamma$ - $\mathrm{Ag}_{2} \mathrm{Al}$ derived porous Ag matrix.1: $\alpha$-Al; $2: \gamma-\mathrm{Ag}_{2} \mathrm{Al}$; 3 : porous $\mathrm{Ag}$ derived from $\alpha-\mathrm{Al}$ phase; 4 :porous $\mathrm{Ag}$ derived from $\gamma-\mathrm{Ag}_{2} \mathrm{Al}$ phase. 


\subsection{Surface areas of the de-aluminized samples}

The fine porous structures shown in Fig.2 is also consistent with the BET surface area analysis of the same bulk samples. Table 1 compares specific surface areas of two dealuminized bulk samples with the traditional pore-former derived counterpart. The details about traditional pore-former method can be found in [29]. The samples de-aluminized in $3 \mathrm{M} \mathrm{HCl}$ at $90^{\circ} \mathrm{C}$ for $48 \mathrm{~h}$ and $72 \mathrm{~h}$ (denoted as $48 \mathrm{~h}-\mathrm{Ag} 50 \mathrm{Al} 50$ and $72 \mathrm{~h}-\mathrm{Ag} 50 \mathrm{Al} 50$, respectively) exhibit 5-6× higher specific surface areas than the traditional pore-former counterpart, demonstrating the capability of chemical dealloying to produce highly porous materials. It is worth mentioning that the BET measurements were performed on bulk samples $(\phi 17 \mathrm{mmx} 1 \mathrm{~mm}$ pellets). The relatively low total surface areas compared to powder samples are, therefore, understandable. This is also why we used $\mathrm{Kr}$ instead of $\mathrm{N}_{2}$ as the adsorption gas.

Table 1. Comparison of BET specific surface area between porous Ag matrices prepared by different methods

\begin{tabular}{ccc}
\hline Sample ID & $\begin{array}{c}\text { BET specific surface } \\
\text { area }\left(\mathrm{m}^{2} / \mathrm{g}\right)\end{array}$ & Fabrication method \\
\hline Ag50C50 & 0.049 & Carbon black pore former \\
$48 \mathrm{~h}-\mathrm{Ag} 50 \mathrm{~A} 150$ & 0.301 & De-aluminizing in $3 \mathrm{M} \mathrm{HCl} \mathrm{at} 90^{\circ} \mathrm{C}$ for $48 \mathrm{~h}$ \\
$72 \mathrm{~h}-\mathrm{Ag} 50 \mathrm{~A} 150$ & 0.287 & De-aluminizing in $3 \mathrm{M} \mathrm{HCl} \mathrm{at} 90^{\circ} \mathrm{C}$ for $72 \mathrm{~h}$ \\
\hline
\end{tabular}




\subsection{Flux density vs temperature}

The permeation flux densities of $\mathrm{CO}_{2}$ and $\mathrm{O}_{2}$ measured from the $48 \mathrm{~h}-50 \mathrm{Ag} 50 \mathrm{Al}$ sample are shown in Fig. 3 as a function of temperature under a simulated flue gas containing 15\% $\mathrm{CO}_{2}, 10 \% \mathrm{O}_{2}$ and $75 \% \mathrm{~N}_{2}$ as the feed gas and a $9.41 \% \mathrm{H}_{2}$-Ar as the sweep gas. Both $\mathrm{CO}_{2}$ and $\mathrm{O}_{2}$ flux densities follow closely the Arrhenius relationship, indicating that the $\mathrm{CO}_{2}$ and $\mathrm{O}_{2}$ rates of transport are thermally activated. In addition, the close activation energies for $\mathrm{CO}_{2}$ and $\mathrm{O}_{2}$ flux densities, viz. 44.6 vs $45.2 \mathrm{~kJ} / \mathrm{mol}$, indicates that the $\mathrm{CO}_{2}$ and $\mathrm{O}_{2}$ fluxes are tightly coupled. The previously mentioned surface reaction of $\mathrm{CO}_{2}+1 / 2 \mathrm{O}_{2}+2 \mathrm{e}^{-}$ $=\mathrm{CO}_{3}{ }^{2-}$ is the primary reason that both $\mathrm{CO}_{2}$ and $\mathrm{O}_{2}$ are simultaneously needed in order for $\mathrm{CO}_{3}{ }^{2-}$ to form and be transported across the membrane.

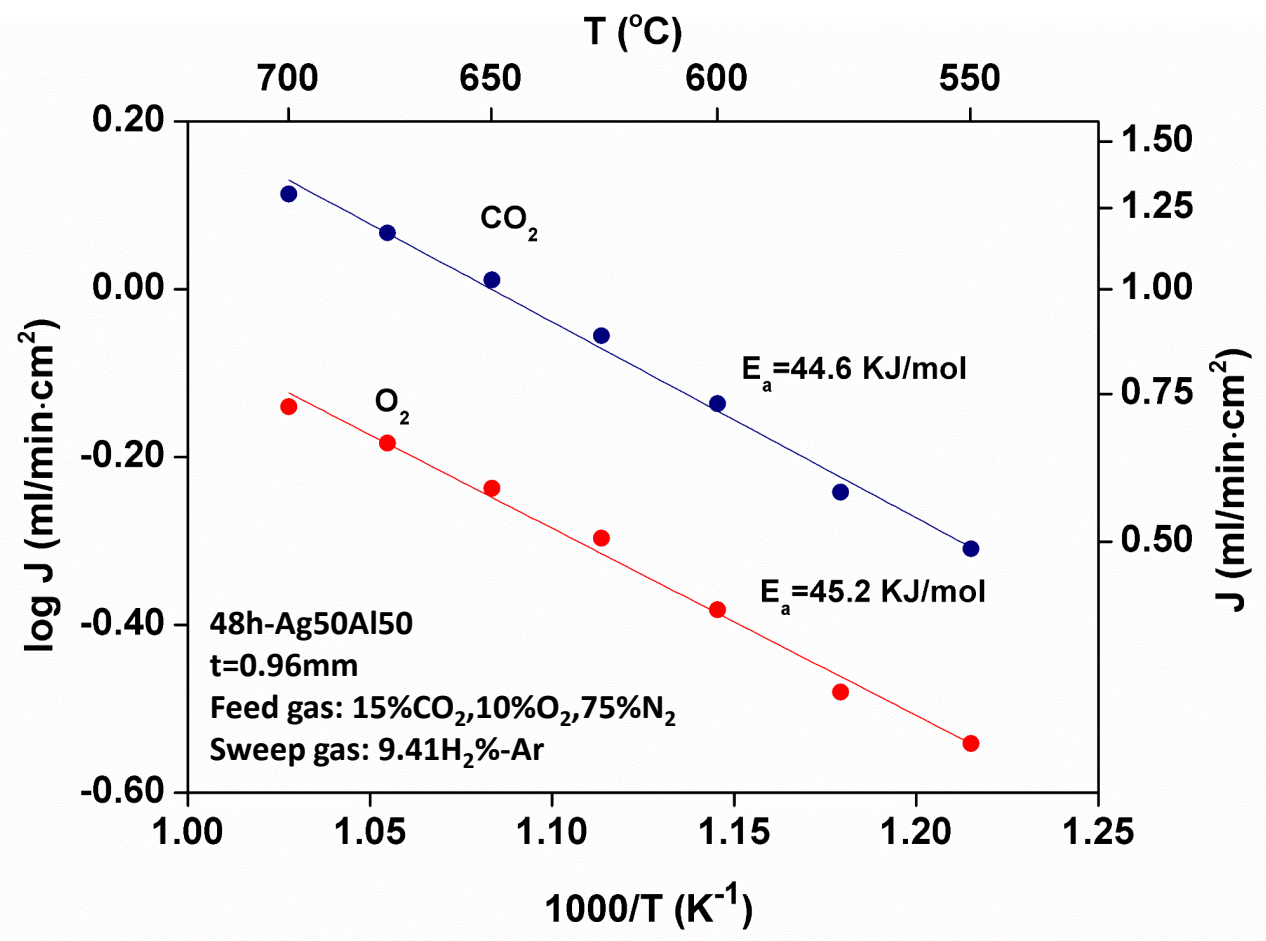

Fig.3 Arrhenius plots of $\mathrm{CO}_{2}$ and $\mathrm{O}_{2}$ flux density of sample 48h-Ag50A150. Feed gas: simulated flue gas containing $15 \% \mathrm{CO}_{2}, 10 \% \mathrm{O}_{2}$, and $75 \% \mathrm{~N}_{2}$; sweep gas: $9.41 \% \mathrm{H}_{2}-\mathrm{Ar}$ 
The level of $\mathrm{CO}_{2}$ flux density achieved by this membrane is also remarkable: $1.30,1.02$ and $0.73 \mathrm{ml} \cdot \mathrm{min}^{-1} \cdot \mathrm{cm}^{-2}$ for 700,650 and $600^{\circ} \mathrm{C}$, respectively. Compared to previous studies using carbon black as a pore former [19-21], the $\mathrm{CO}_{2}$ flux density achieved in this study is $3 \times$ higher. What is also intriguing from Fig. 3 is that the flux ratio between $\mathrm{CO}_{2}$ and $\mathrm{O}_{2}$ deviates from the ideal 2:1 to (1.71-1.79):1 in the temperature range of 550 to $700^{\circ} \mathrm{C}$. This new flux ratio falls in between $2: 1$ to $1: 1.5$ with the former ratio signaling $\mathrm{CO}_{3}{ }^{2-}$ as the active surface species and the latter ratio inferring $\mathrm{CO}_{4}{ }^{2-}$ as the active surface species [36]. Therefore, the presence of both $\mathrm{CO}_{3}{ }^{2-}$ and $\mathrm{CO}_{4}{ }^{2-}$ species on the surface of a chemically dealloyed silver-carbonate membrane is possible. Based on this understanding, surface reactions of the primary reaction of $\mathrm{CO}_{2}+1 / 2 \mathrm{O}_{2}+2 \mathrm{e}^{-}=\mathrm{CO}_{3}{ }^{2-}$ $\left(\mathrm{CO}_{2}: \mathrm{O}_{2}=2: 1\right)$ accompanied by the secondary reaction of $\mathrm{CO}_{2}+3 / 2 \mathrm{O}_{2}+\mathrm{CO}_{3}{ }^{2-}+2 \mathrm{e}^{-}=2 \mathrm{CO}_{4}{ }^{2-}$ $\left(\mathrm{CO}_{2}: \mathrm{O}_{2}=1: 1.5\right)$ are likely to occur simultaneously. The observed higher activation energies here compared to $32 \mathrm{~kJ} / \mathrm{mol}$ for $\mathrm{CO}_{3}{ }^{2-}$ conduction in pure molten carbonates [37] as well as the experimental observation of $\mathrm{CO}_{4}{ }^{2-}$ on the surface of $\mathrm{MC}$ [36] seem to support the theory that a bulkier $\mathrm{CO}_{4}{ }^{2-}$ may be involved in the $\mathrm{CO}_{2}$ and $\mathrm{O}_{2}$ transport.

It is worth mentioning that both $\mathrm{CO}_{2}$ and $\mathrm{O}_{2}$ can be transported through a MECC membrane as suggested by the enabling surface reaction shown above, which makes the membrane not strictly $\mathrm{CO}_{2}$ selective. However, use of a fuel as the sweep gas such as $\mathrm{H}_{2}$ and/or $\mathrm{CO}$ to react with $\mathrm{O}_{2}$ can form a stream containing only $\mathrm{CO}_{2}$ and $\mathrm{H}_{2} \mathrm{O}$ following the reactions of $\mathrm{H}_{2}+\mathrm{CO}_{3}{ }^{2-}=\mathrm{CO}_{2}+\mathrm{H}_{2} \mathrm{O}+2 \mathrm{e}^{-}+\Delta$ (heat) and $\mathrm{CO}+\mathrm{CO}_{3}{ }^{2-}=2 \mathrm{CO}_{2}+2 \mathrm{e}^{-}+\Delta$. The yielded $\left(\mathrm{CO}_{2}+\mathrm{H}_{2} \mathrm{O}+\Delta\right)$ product can be either condensed out to obtain separate $\mathrm{H}_{2} \mathrm{O}$ 
and $\mathrm{CO}_{2}$ or fed into a high-temperature solid-oxide electrolyzer to convert $\mathrm{CO}_{2}$ and $\mathrm{H}_{2} \mathrm{O}$ into syngas. The reuse of captured $\mathrm{CO}_{2}$ to make syngas has an important implication to the realization of a carbon-neutral energy future.

\subsection{The effect of $\mathrm{H}_{2}$ in sweep gas on flux density}

From a performance point of view, use of fuel as sweep gas also increases the gradient of chemical potential of $\mathrm{O}_{2}$ across the membrane, thus enhancing $\mathrm{J}_{\mathrm{O} 2}$ as well as $\mathrm{J}_{\mathrm{CO} 2}$ because of the coupled $\mathrm{CO}_{2}-\mathrm{O}_{2}$ transport. Therefore, the effect of adding $\mathrm{H}_{2}$ into Ar as sweep gas on flux densities of $\mathrm{CO}_{2}$ and $\mathrm{O}_{2}$ was particularly explored in this study. Fig.4 shows $\mathrm{J}_{\mathrm{CO} 2}$ and $\mathrm{J}_{\mathrm{O} 2}$ measured at $600^{\circ} \mathrm{C}$ with different $\mathrm{H}_{2}$ concentrations in $\mathrm{Ar}$ as the sweep gas during a period of the lifetime of the membrane. The results indicate that $\mathrm{J}_{\mathrm{CO} 2}$ and $\mathrm{J}_{\mathrm{O} 2}$ with $9.41 \% \mathrm{H}_{2}-\mathrm{Ar}$ are the highest, approximately $1.5 \times$ higher than $4.35 \% \mathrm{H}_{2}-\mathrm{Ar}$ and $2 \times$ higher than pure Ar, confirming that lowering partial pressure of $\mathrm{O}_{2}$ can indeed significantly enhance both $\mathrm{CO}_{2}$ and $\mathrm{O}_{2}$ flux densities. It is to be noted that the higher $\mathrm{CO}_{2}$ flux shown in Fig. 4 than in Fig.3 is resulted from the fact that the flux density improves with time; data shown in Fig. 3 were measured at the beginning of the test whereas those in Fig.4 were measured after $160 \mathrm{~h}$ on-test. Overall, the enhanced flux density by $\mathrm{H}_{2}$ in conjunction with the aforementioned product of $\left(\mathrm{CO}_{2}+\mathrm{H}_{2} \mathrm{O}+\Delta\right)$ enabled by the use of a fuel as the sweep gas and flue gas as the feed gas promises that MECC membranes will be an important carbon-neutral technology in the future. 


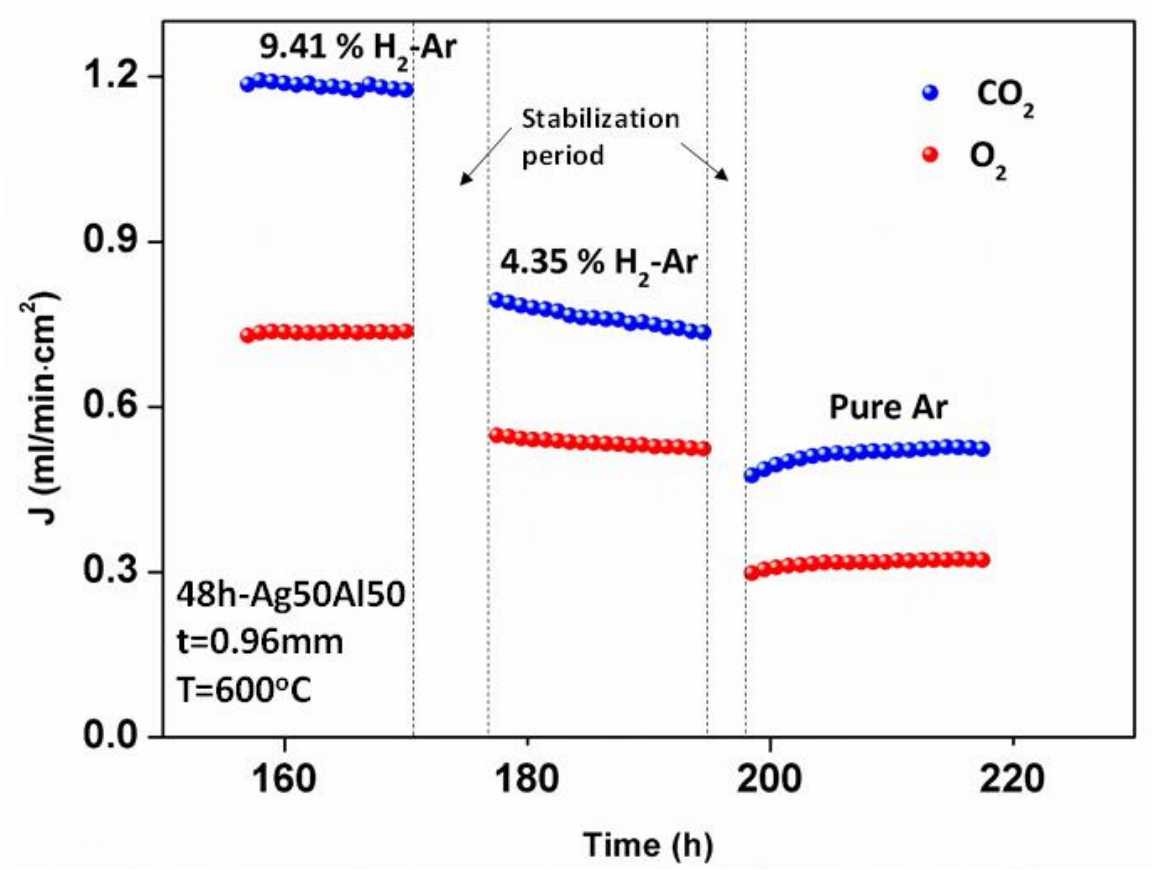

Fig. 4 The effect of $\mathrm{H}_{2}$ concentration in the sweep gas on $\mathrm{CO}_{2}$ and $\mathrm{O}_{2}$ flux densities. Feed gas: $15 \% \mathrm{CO}_{2}, 10 \% \mathrm{O}_{2}$, and $75 \% \mathrm{~N}_{2}$.

\subsection{Long-term flux stability test}

The long-term stability of MECC membranes has been a major issue in the past. The much improved long-term stability of the chemical-dealloying derived silver-carbonate MECC membrane is shown clearly in Fig.5. Over the entire 900-h testing period, $\mathrm{J}_{\mathrm{CO} 2}$ and $\mathrm{J}_{\mathrm{O} 2}$ did not show significant degradation despite some fluctuations at the beginning. The fluxes became virtually stable after the first 100 -h initialization period for the following nearly 800 hours. While it is not exactly clear why there was a sharp decrease in flux during the first 100-h followed by a recovery, the retention of a high flux has never been observed for so long a period of time for our baseline pore-former derived membranes as 
well as those modified by $\mathrm{Al}_{2} \mathrm{O}_{3}[19-21]$. We believe that the stable performance achieved demonstrates the importance of creating sufficiently small pores in a porous silver matrix, by which loss of molten carbonate, a leading cause for flux degradation, can be effectively alleviated. The test was eventually terminated due to an increased $\mathrm{N}_{2}$ leakage from $0 \%$ at the beginning to $1.5 \%$ at $900-\mathrm{h}$ marker, indicating a significant loss of carbonate occurred. It is also worth mentioning that $\mathrm{N}_{2}$ leakage gradually increases with time during the course of experiment, indicating a gradual loss of molten carbonate.

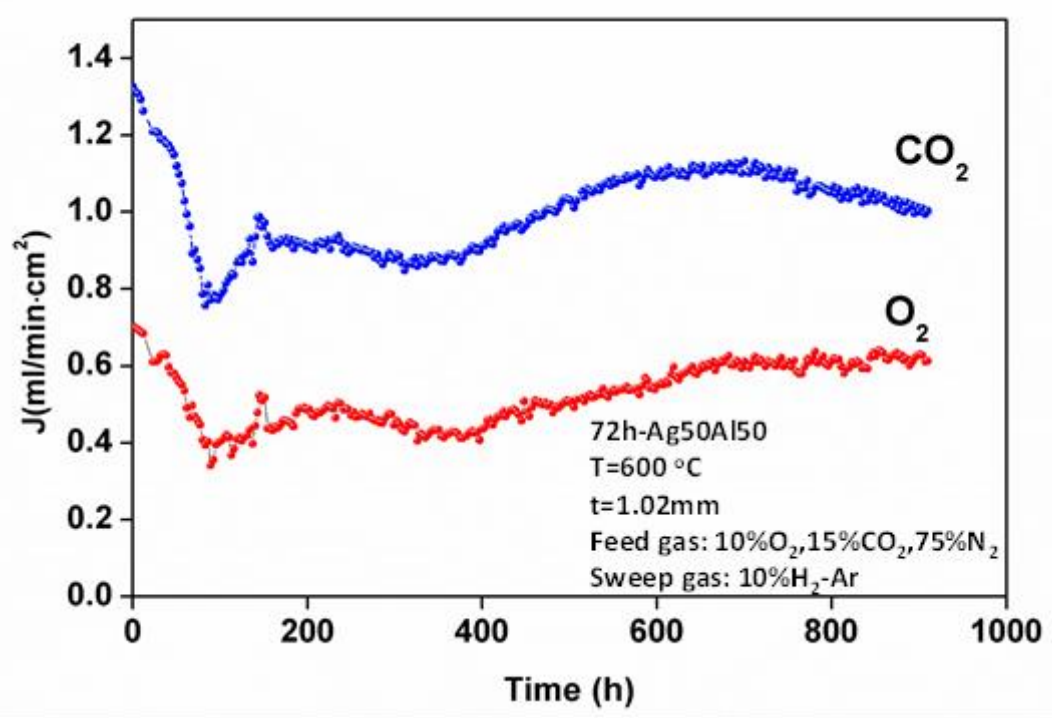

Fig. $5 \mathrm{CO}_{2}$ and $\mathrm{O}_{2}$ flux densities as a function of time operated at $600^{\circ} \mathrm{C}$ under a simulated flue gas $10 \% \mathrm{O}_{2}, 15 \% \mathrm{CO}_{2}$ and $75 \% \mathrm{~N}_{2}$ as the feed gas and $9.41 \% \mathrm{H}_{2}$ - $\mathrm{Ar}$ as the sweep gas.

Microstructural comparison of the post-test sample with the pre-test one is shown in Fig.6; it suggests that a significant growth of silver grains has occurred during the 900-h testing. The grain growth gradually squeezed out molten carbonate and eventually resulted in a gas breakthrough. The observed flux fluctuations in Fig. 5 could also be 
related to the silver sintering, during which MC's mobility and thickness varied with time. Preventing silver from sintering appears to be necessary for future development. With the high-flux exhibited by using a fuel as the sweep gas, the operating temperature can be further decreased to a temperature such as $500^{\circ} \mathrm{C}$ as a means of alleviating the silver sintering.

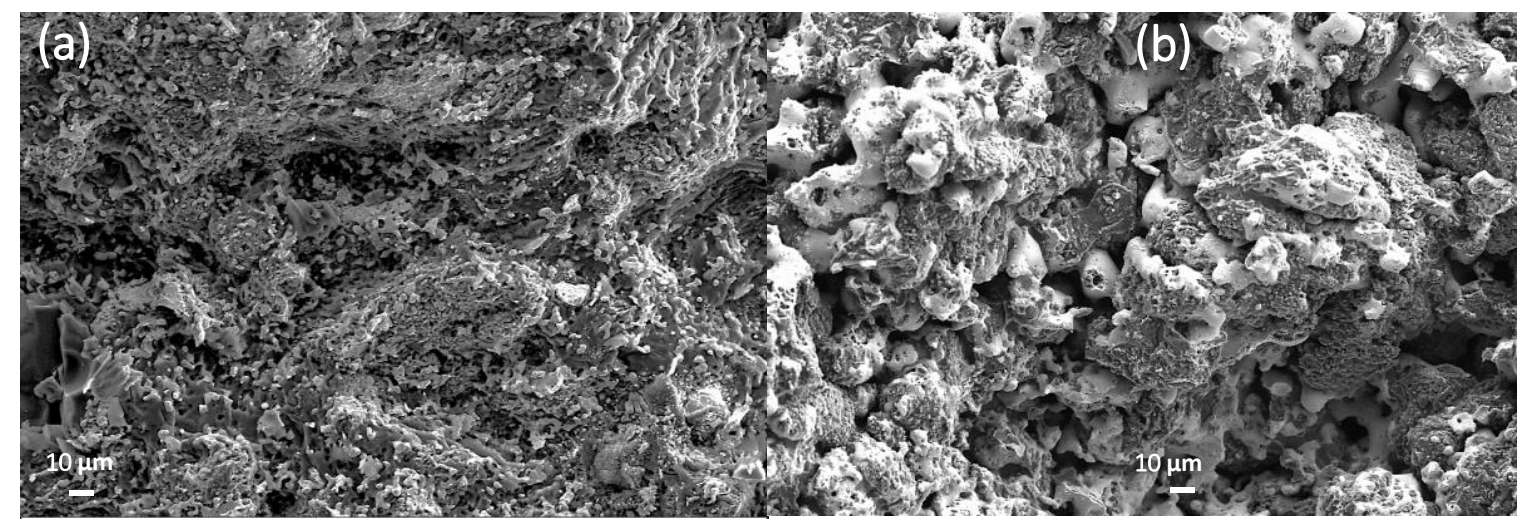

Fig.6 Microstructures of chemical dealloyed MECC membrane. (a) Pre-test; (b) post-test

\section{Conclusion}

A high-flux and stable silver-carbonate based electrochemical carbon capture membrane has been successfully demonstrated with the porous silver matrix fabricated by a chemical dealloying method. The SEM analysis shows that the resultant porous Ag matrix contains long 3D channels, micron and sub-micron pores created from intergranular corrosion, $\alpha-$ $\mathrm{Al}$ and $\gamma-\mathrm{Ag}_{2} \mathrm{Al}$ phase, respectively. The observed similar activation energy for $\mathrm{J}_{\mathrm{CO} 2}$ and $\mathrm{J}_{\mathrm{O} 2}$ suggests a coupled transport mechanism for $\mathrm{CO}_{2}$ and $\mathrm{O}_{2}$. The lowered $\mathrm{J}_{\mathrm{CO} 2}: \mathrm{J}_{\mathrm{O} 2}$ from the expected 2:1 ratio signals the involvement of $\mathrm{CO}_{4}{ }^{2-}$ as an active surface species. The study also demonstrates that the presence of $\mathrm{H}_{2}$ in the sweep gas can significantly 
enhance the flux of $\mathrm{CO}_{2}$ and $\mathrm{O}_{2}$ as a result of increased chemical potential gradient of $\mathrm{O}_{2}$. More important, the captured stream contains only $\mathrm{CO}_{2}$ and $\mathrm{H}_{2} \mathrm{O}$ with laden heat, which is an ideal feedstock for a high-temperature solid-oxide electrolyzer to convert $\mathrm{CO}_{2} / \mathrm{H}_{2} \mathrm{O}$ back into syngas $\mathrm{CO} / \mathrm{H}_{2}$. Also, the long-term stability test shows that a high and stable $\mathrm{CO}_{2} / \mathrm{O}_{2}$ flux can be retained for $\sim 900$ hours, demonstrating the potential of chemical dealloying as a method to make robust MECC membranes for future benchtop testing.

\section{Acknowledgement}

Financial support from NSF (CBET-1340269, CBET-1401280) is greatly appreciated.

\section{References}

[1] N. MacDowell, N. Florin, A. Buchard, J. Hallett, A. Galindo, G. Jackson, C.S. Adjiman, C.K. Williams, N. Shah, P. Fennell, An overview of CO2 capture technologies, Energy \& Environmental Science, 3 (2010) 1645-1669.

[2] M.E. Boot-Handford, J.C. Abanades, E.J. Anthony, M.J. Blunt, S. Brandani, N. Mac Dowell, J.R. Fernandez, M.C. Ferrari, R. Gross, J.P. Hallett, R.S. Haszeldine, P. Heptonstall, A. Lyngfelt, Z. Makuch, E. Mangano, R.T.J. Porter, M. Pourkashanian, G.T. Rochelle, N. Shah, J.G. Yao, P.S. Fennell, Carbon capture and storage update, Energy \& Environmental Science, 7 (2014) 130-189.

[3] DOE/NETL, Carbon dioxide capture and storage RD\&D roadmap, (December 2010).

[4] DOE/NETL, Advanced carbon dioxide capture R\&D program: technology update, (September 2010).

[5] DOE/BES, Basic research needs for carbon capture: beyond 2020, (March 2010).

[6] R. Bredesen, K. Jordal, A. Bolland, High-temperature membranes in power generation with $\mathrm{CO} 2$ capture, Chemical Engineering and Processing, 43 (2004) 1129-1158.

[7] B.J.P. Buhre, L.K. Elliott, C.D. Sheng, R.P. Gupta, T.F. Wall, Oxy-fuel combustion technology for coalfired power generation, Progress in Energy and Combustion Science, 31 (2005) 283-307.

[8] M.O. Franklin, 8, Energy \& Environmental Science, 2 (2009) 449-458.

[9] E. Favre, Carbon dioxide recovery from post-combustion processes: Can gas permeation membranes compete with absorption?, Journal of Membrane Science, 294 (2007) 50-59.

[10] Y. Zhang, J.Y.G. Chan, Sustainable chemistry: imidazolium salts in biomass conversion and $\mathrm{CO} 2$ fixation, Energy \& Environmental Science, 3 (2010) 408-417.

[11] J. Winnick, H. Toghiani, P.D. Quattrone, CARBON-DIOXIDE CONCENTRATION FOR MANNED SPACECRAFT USING A MOLTEN CARBONATE ELECTROCHEMICAL-CELL, Aiche Journal, 28 (1982) 103-111. 
[12] J.L. Weaver, J. Winnick, THE MOLTEN CARBONATE CARBON-DIOXIDE CONCENTRATOR - CATHODE PERFORMANCE AT HIGH CO2 UTILIZATION, Journal of the Electrochemical Society, 130 (1983) 20-28.

[13] L. Zhang, X. Li, S. Wang, K.G. Romito, K. Huang, High conductivity mixed oxide-ion and carbonate-ion conductors supported by a prefabricated porous solid-oxide matrix, Electrochemistry Communications, 13 (2011) 554-557.

[14] L. Zhang, N. Xu, X. Li, S. Wang, K. Huang, W.H. Harris, W.K.S. Chiu, High CO2 permeation flux enabled by highly interconnected three-dimensional ionic channels in selective $\mathrm{CO} 2$ separation membranes, Energy \& Environmental Science, 5 (2012) 8310-8317.

[15] L. Zhang, Z. Mao, J.D. Thomason, S. Wang, K. Huang, Synthesis of a Homogeneously Porous Solid Oxide Matrix with Tunable Porosity and Pore Size, Journal of the American Ceramic Society, 95 (2012) 1832-1837.

[16] J. Tong, L. Zhang, J. Fang, M. Han, K. Huang, Electrochemical Capture of CO2 from Natural Gas Using a High-Temperature Ceramic-Carbonate Membrane, Journal of the Electrochemical Society, 162 (2015) E43-E46.

[17] J. Tong, L. Zhang, M. Han, K. Huang, Electrochemical separation of $\mathrm{CO} 2$ from a simulated flue gas with high-temperature ceramic-carbonate membrane: New observations, Journal of Membrane Science, 477 (2015) 1-6.

[18] N. Xu, X. Li, M.A. Franks, H. Zhao, K. Huang, Silver-molten carbonate composite as a new high-flux membrane for electrochemical separation of $\mathrm{CO} 2$ from flue gas, Journal of Membrane Science, 401 (2012) 190-194.

[19] L. Zhang, J. Tong, Y. Gong, M. Han, S. Wang, K. Huang, Fast electrochemical CO2 transport through a dense metal-carbonate membrane: A new mechanistic insight, Journal of Membrane Science, 468 (2014) 373-379.

[20] L. Zhang, Y. Gong, J. Yaggie, S. Wang, K. Romito, K. Huang, Surface modified silver-carbonate mixed conducting membranes for high flux $\mathrm{CO} 2$ separation with enhanced stability, Journal of Membrane Science, 453 (2014) 36-41.

[21] J. Tong, F. Si, L. Zhang, J. Fang, M. Han, K. Huang, Stabilizing electrochemical carbon capture membrane with Al2O3 thin-film overcoating synthesized by chemical vapor deposition, Chemical Communications, 51 (2015) 2936-2938.

[22] X. Dong, J.O. Landeros, Y.S. Lin, An asymmetric tubular ceramic-carbonate dual phase membrane for high temperature CO2 separation, Chemical Communications, 49 (2013) 9654-9656.

[23] Z.B. Rui, M. Anderson, Y.D. Li, Y.S. Lin, Ionic conducting ceramic and carbonate dual phase membranes for carbon dioxide separation, Journal of Membrane Science, 417 (2012) 174-182.

[24] Y.D. Li, Z.B. Rui, C. Xia, M. Anderson, Y.S. Lin, Performance of ionic-conducting ceramic/carbonate composite material as solid oxide fuel cell electrolyte and $\mathrm{CO} 2$ permeation membrane, Catalysis Today, 148 (2009) 303-309.

[25] Z.B. Rui, M. Anderson, Y.S. Lin, Y.D. Li, Modeling and analysis of carbon dioxide permeation through ceramic-carbonate dual-phase membranes, Journal of Membrane Science, 345 (2009) 110-118.

[26] Y.C. Zhao, C. Xia, Y.J. Wang, Z.R. Xu, Y.D. Li, Quantifying multi-ionic conduction through doped ceriacarbonate composite electrolyte by a current-interruption technique and product analysis, International Journal of Hydrogen Energy, 37 (2012) 8556-8561.

[27] Y.C. Zhao, C. Xia, Z.R. Xu, Y.D. Li, Validation of H+/O2- conduction in doped ceria-carbonate composite material using an electrochemical pumping method, International Journal of Hydrogen Energy, 37 (2012) 11378-11382.

[28] Y.C. Zhao, Z.R. Xu, C. Xia, Y.D. Li, Oxide ion and proton conduction in doped ceria-carbonate composite materials, International Journal of Hydrogen Energy, 38 (2013) 1553-1559. 
[29] L.L. Zhang, Y.H. Gong, K.S. Brinkman, T. Wei, S.W. Wang, K. Huang, Flux of silver-carbonate membranes for post-combustion $\mathrm{CO} 2$ capture: The effects of membrane thickness, gas concentration and time, Journal of Membrane Science, 455 (2014) 162-167.

[30] T.T. Norton, B. Lu, Y.S. Lin, Carbon dioxide permeation properties and stability of samarium-dopedceria carbonate dual-phase membranes, Journal of Membrane Science, 467 (2014) 244-252.

[31] J.L. Wade, C. Lee, A.C. West, K.S. Lackner, Composite electrolyte membranes for high temperature CO2 separation, Journal of Membrane Science, 369 (2011) 20-29.

[32] J. Erlebacher, M.J. Aziz, A. Karma, N. Dimitrov, K. Sieradzki, Evolution of nanoporosity in dealloying, Nature, 410 (2001) 450-453.

[33] Desk Handbook: Phase Diagrams for Binary Alloys edited by H. Okamoto, ASM International, Materials Park, OH, 2000.

[34] M. A, The Ag-Al (Silver-Aluminum) System, Bulletin of Alloy Phase Diagram, 8 (1987) 526-527.

[35] M.-S. Kim, H. Nishikawa, Fabrication of nanoporous silver and microstructural change during

dealloying of melt-spun Al-20 at.\%Ag in hydrochloric acid, Journal of Materials Science, 48 (2013) 5645-

5652.

[36] L.J. Chen, C.J. Lin, J. Zuo, L.C. Song, C.M. Huang, First spectroscopic observation of peroxocarbonate/peroxodicarbonate in molten carbonate, Journal of Physical Chemistry B, 108 (2004) 7553-7556.

[37] G.T. Rochelle, Amine Scrubbing for CO2 Capture, Science, 325 (2009) 1652-1654. 